\title{
INCLUSÃo E INOVAÇÃO PEDAGÓGICA: POLÍTICAS E PRÁTICAS DE FORMAÇÃO NO ENSINO SUPERIOR
}

\author{
INCLUSION AND PEDAGOGICAL INNOVATION: POLICIES AND \\ PRACTICES FOR FORMATION IN HIGHER EDUCATION
}

\author{
INCLUSIÓN E INNOVACIÓN PEDAGÓGICA: POLÍTICAS Y PRÁCTICAS \\ DE FORMACIÓN EN LA ENSEÑANZA SUPERIOR
}

\author{
Marco Antônio Melo FRANCO ${ }^{1}$ \\ Marcilene Magalhães da SILVA ${ }^{2}$ \\ Edmilson Minoru TORISU ${ }^{3}$
}

RESUMO: Nas propostas educacionais que privilegiam equidade e igualdade de oportunidades entre os diferentes sujeitos, pretende-se que a concepção de inclusão contribua para superar atitudes de indiferença e intolerância, estabelecendo uma disposição para a construção de culturas que respeitem e valorizem as diferenças humanas. Este estudo busca analisar como a política institucional de apoio aos estudantes com deficiência da Universidade Federal de Ouro Preto e um dos projetos extensionistas no campo da inclusão, desenvolvidos no Departamento de Educação, colaboram para o fortalecimento de uma postura inovadora e inclusiva. Essas ações institucionais e acadêmicas apontam para a necessidade de refletir sobre a função social das universidades e a constituição de um espaço formativo mais inclusivo.

PALAVRAS-CHAVE: Educação superior. Inclusão. Inovação pedagógica.

RESUMEN: En las propuestas educativas que privilegian equidad y igualdad de oportunidades entre los diferentes sujetos, se pretende que la concepción de inclusión contribuya a superar actitudes de indiferencia y intolerancia estableciendo una disposición para la construcción de culturas que respeten y valoren las diferencias humanas. Este estudio busca analizar cómo la política institucional de apoyo a los estudiantes con discapacidad de la Universidad Federal de Ouro Preto y uno de los

${ }^{1}$ Universidade Federal de Minas Gerais (UFMG), Belo Horizonte - MG - Brasil. Professor Adjunto do Departamento de Educação e do Programa de Pós-Graduação em Educação da UFOP. Doutor em Ciências da Saúde - UFMG. Membro do Observatório Internacional de Inclusão, Interculturalidade e Inovação Pedagógica (OIIIIP). $\quad$ ORCID: <http://orcid.org/0000-0002-0159-4109>. E-mail: <mamf.franco@gmail.com>.

2 Universidade Federal de Ouro Preto (UFOP), Ouro Preto - MG - Brasil. Técnica em Assuntos Educacionais da UFOP. Mestre em Educação - UFOP. Membro do Observatório Internacional de Inclusão, Interculturalidade e Inovação Pedagógica (OIIIIPe). ORCID: <https://orcid.org/0000-0001-7304-6817>. Email: <marcilenemag@gmail.com>.

3 Universidade Federal de Ouro Preto (UFOP), Ouro Preto - MG - Brasil. Professor Adjunto do Departamento de Matemática da UFOP. Doutor em Educação (linha de pesquisa Educação Matemática) UFMG. Membro do Observatório Internacional de Inclusão, Interculturalidade e Inovação Pedagógica (OIIIIPe). ORCID: <http://orcid.org/0000-0001-7383-387X>. E-mail: <etorisu@gmail.com>.

RIAEE - Revista Ibero-Americana de Estudos em Educação, Araraquara, v. 13. n. esp. 2, p. 1320-1333, set., 2018. ISSN: $1982-5587$. 
proyectos extensionistas en el campo de la inclusión, desarrollados en el Departamento de Educación, contribuyen al fortalecimiento de una postura innovadora e inclusiva. Estas acciones institucionales y académicas apuntan a la necesidad de reflexionar sobre la función social de las universidades y la constitución de un espacio formativo más inclusivo.

PALABRAS CLAVE: Enseñanza superior. Inclusión. Innovación pedagógica.

ABSTRACT: In the educational proposals that favour equity and equal opportunities among the different individuals, it is intended that the concept of inclusion contribute to overcome attitudes of indifference and intolerance by establishing a willingness to construct cultures that respect and value human differences. This study aims to analyse how the institutional policy of support to students with disabilities of the Federal University of Ouro Preto and also one of the extension projects in the field of inclusion, developed in the Department of Education, contribute to the strengthening of an innovative and inclusive posture. These institutional and academic actions indicate the need of reflection on the social function of universities and the constitution of a more inclusive formative space.

KEYWORDS: Higher education. Inclusion. Pedagogical innovation.

\section{Introdução}

Para Ainscow (2009), a inclusão educacional deve ser considerada como o maior desafio do atual sistema escolar, em todos os seus níveis, etapas e modalidades. Propostas educacionais inovadoras e inclusivas, fundamentadas no direito à igualdade de oportunidades e de dignidade para todos, ganham a pauta nos debates científicos em âmbitos nacional e internacional, que ocorrem em defesa da construção de uma cultura inclusiva alicerçada no respeito às diferenças e na negação de qualquer tipo de atitude de indiferença e de intolerância com relação a elas.

Ao considerarmos essa perspectiva, é importante voltarmos nosso olhar para a universidade e as práticas pedagógicas que nela, muitas vezes, se cristalizaram. Essas práticas, por vezes, podem revelar dificuldades da instituição na consolidação de seu papel social e inclusivo, as quais nos levam a questionar o papel da universidade em uma sociedade cujas mudanças ocorrem a uma velocidade espantosa. Será que a universidade tem respondido às demandas que a sociedade manifesta? Estaria essa instituição em endogenia tamanha a ponto de não conseguir estreitar o diálogo entre o acadêmico e o social? Essas questões nos atentam para a necessidade de debater e discutir o que se tem 
produzido no campo do Ensino Superior que aponte para perspectivas mais inclusivas e para que ultrapassem seus muros e abram o diálogo com a sociedade.

Ao levantarmos tais questões, é preciso salientar que, historicamente, as instituições escolares, incluindo as universidades, assumiram uma perspectiva positivista do conhecimento, fundamentada na racionalidade técnica, e que esse modelo ainda se encontra, de certa forma, embrenhado nas suas ações e formas de pensar. A dicotomia entre sujeito e objeto, teoria e prática, corpo e mente, natureza e cultura, engessa nossas ações ao propalar uma visão nada indulgente com relação àquilo que não passe pelo crivo da ciência.

Em âmbito um pouco mais amplo, as questões de cunho mais subjetivo e relacionadas aos estudantes são deixadas de lado, pois não cabem no bojo do que se discute no campo das ciências. Em outras palavras, os estudantes acabam por ocupar o lugar de receptores, desprovidos de protagonismos e, de alguma maneira, assujeitados aos conhecimentos científicos transmitidos por professores, a exemplo da Educação Bancária de Paulo Freire.

Tudo isso se apresenta na contramão das novas propostas educacionais que defendem a promoção de igualdade de oportunidades e dignidade para todos. É importante ressaltar que a universidade não deve ignorar o fato de que "não está imune aos sismos sociais que vão progressivamente atingindo seu contexto" (CUNHA, 2016, p. 89). Sendo assim, embora nos pareça óbvio que essas novas propostas educacionais possam ser um caminho para a construção de uma universidade verdadeiramente inclusiva, é importante interrogar como elas têm sido compreendidas e implementadas.

Quando falamos de novas propostas educacionais, é possível compreendê-las de diferentes maneiras. Aqui nos interessam, em particular, aquelas voltadas a inovações pedagógicas que possam, em alguma medida, sugerir alternativas para novos saberes e experiências desenvolvidos no âmbito acadêmico das universidades e que possibilitem aos estudantes e profissionais a sua emergência e a realização de experiências que estejam para além do modelo de racionalidade técnica e das dicotomias entre a teoria e prática, senso comum e ciência, cultura e natureza. A perspectiva de inovação pedagógica aparece aqui como mudança paradigmática, conforme nos define Cunha (2016). Ademais, consideramos que inovação pedagógica deve ser aquela em cuja essência residem concepções e ações de inclusão. 
Ao longo do texto, trataremos, em um primeiro momento, dos conceitos de inclusão e de inovação pedagógica. Posteriormente, apresentaremos dados da Universidade Federal de Ouro Preto (UFOP). ${ }^{4}$ Nosso objetivo é evidenciar como a política institucional de apoio aos estudantes com deficiência dos cursos de graduação da UFOP e um dos projetos extensionistas de formação inicial, desenvolvidos no curso de Pedagogia (Departamento de Educação), têm contribuído para o fortalecimento de uma postura inovadora e inclusiva.

\section{Inclusão, inovação pedagógica e o contexto da Universidade Federal de Ouro Preto}

No Brasil dos últimos anos, pôde-se notar um avanço no processo de democratização do ensino superior. A interiorização desse nível de ensino, provocada pela criação de novas universidades e institutos federais, além do surgimento de inúmeras instituições privadas, aumentou consideravelmente a oferta de vagas. Podemos somar a isso as políticas públicas que promovem o financiamento estudantil e a entrada na universidade pelo sistema de cotas para notarmos que muita coisa melhorou em termos de acesso ao Ensino Superior.

Entretanto, não se pode dizer o mesmo com relação à preparação das universidades para receber os estudantes. Se, por um lado, o Brasil caminhou adiante na direção de democratizar o acesso às universidades, de outro, o modus operandi das atividades de ensino, nessas instituições, parece andar a passos lentos e, por vezes, estagnado no tempo.

As ações pedagógicas que possibilitem uma democratização das convivências, que tenham como base o respeito às diferenças e que questionem o paradigma racionalista do fazer pedagógico na universidade são fundamentais para a modificação do modelo vigente. Para Cunha (2006, p. 65):

A ruptura com a forma tradicional de ensinar e aprender significa, principalmente, compreender o conhecimento a partir de uma perspectiva epistemológica que problematiza os procedimentos acadêmicos inspirados nos princípios positivistas da ciência moderna. Nesse sentido, é preciso compreender as origens das práticas pedagógicas e curriculares que predominantemente se instalam na universidade e na escola.

\footnotetext{
${ }^{4}$ A UFOP está localizada na Região Sudeste, em Minas Gerais, e foi criada em 21 de agosto de 1969, pelo Decreto-lei n. ${ }^{\circ}$ 778, a partir da fusão de duas escolas isoladas, a Escola de Farmácia, fundada em 1839, e a Escola de Minas e Metalurgia, de 1876. No momento da pesquisa, contava com três campi, 11 unidades acadêmicas, 43 cursos de graduação, 68 cursos de pós-graduação, cerca de 13 mil e 400 alunos regularmente matriculados nos cursos de graduação, 847 professores e 808 técnicos administrativos em Educação.
} 
Vistas assim, essas ações podem ser consideradas inovações pedagógicas que, essencialmente, devem ser capazes de promover o respeito aos sujeitos nas suas particularidades e nas suas potencialidades, resguardando o princípio da diferença. A concepção de inovação pedagógica como algo transformador deve possuir em seu bojo uma perspectiva emancipatória capaz de ir além de um modelo regulatório que, até então, rege as políticas e ações educacionais (VEIGA, 2003). Para a autora, a tensão e as relações de poder evidenciam-se quando confrontamos os dois modelos. Fica claro que a perspectiva emancipatória opõe-se ao modelo de racionalidade técnica e traz para o debate uma perspectiva mais inclusiva de pensar o modelo pedagógico de formação.

Quando pensamos em uma educação emancipatória, capaz de promover não somente o acesso, como também a permanência de todos no âmbito das instituições escolares e com garantias do direito a uma educação de qualidade, aproximamos os dois conceitos: inclusão e inovação pedagógica. Entendemos que a discussão isolada destes pouco contribui para refletirmos sobre uma educação que busque a diminuição das desigualdades e que respeite as diferenças. Para Cunha (2008), a inovação não está apenas relacionada ao campo da prática. Ela pressupõe a mudança na forma de compreender o conhecimento, reconfigurando-o para além das regularidades que a modernidade impõe. Essa perspectiva de entender a inovação pedagógica dialoga diretamente com a premissa básica do modelo de inclusão, que diz que:

[...] uma educação inclusiva de qualidade com relação a alunos com deficiência ou distúrbios refere-se à implementação de políticas que possam incluir todos os alunos, ou seja, a busca de melhor qualidade de escolarização de alunos com deficiências ou distúrbios deve se subordinar à melhoria da qualidade do ensino em geral, na perspectiva de atendimento da diversidade do alunado que hoje chega à escola básica (BUENO, 2012, p. 290).

Embora o autor se refira à educação básica em seu texto, podemos estender essa discussão ao ensino superior. A educação brasileira tem, diante de si, o desafio de possibilitar a efetiva participação de todos na vida escolar, numa perspectiva inclusiva, o que requer se preocupar com o apoio à criação de políticas e culturas de inclusão e à organização de pedagogias inovadoras. Portanto, compreender como ocorre esse processo em nossas universidades é fundamental para refletir acerca dos progressos e retrocessos presentes no sistema educativo, o que supõe retomar o tema da igualdade e, 
consequentemente, o da diferença, afirmando a era dos direitos em detrimento dos princípios excludentes.

Nessa perspectiva, analisamos dados da Universidade Federal de Ouro Preto (UFOP) com a intenção de compreender como as ações institucionais de apoio aos estudantes com deficiência dos cursos de graduação e um dos projetos extensionistas, desenvolvidos no curso de Pedagogia, têm contribuído para o fortalecimento de uma postura inovadora e inclusiva. Como procedimento metodológico, foram examinados documentos diversos que tratam da política de inclusão na UFOP. Para Ludke e André (1986), os documentos representam uma fonte riquíssima de informações sobre determinado contexto, podendo ser retiradas daí evidências que fundamentam afirmações dos pesquisadores.

Os passos iniciais do estudo foram mapear e conhecer as ações e práticas sobre inclusão e inovação pedagógica na Instituição. As informações foram obtidas no Colegiado do Curso de Pedagogia, nas pró-reitorias de Graduação e de Extensão e em estudos já realizados na UFOP sobre a temática. A partir da análise documental, selecionamos os seguintes programas, ações e práticas desenvolvidos na UFOP que podem contribuir para o fortalecimento de uma postura inovadora e inclusiva: o Núcleo de Educação Inclusiva, o Programa Sala Aberta e o projeto de extensão de formação inicial intitulado Inclusão: Práticas pedagógicas, aquisição do sistema de escrita e outras aprendizagens.

Nossa intenção aqui é deixar pistas para pensar os desafios que estão postos para a Educação Superior, no sentido de construir saberes pedagógicos inclusivos e inovadores capazes de atender à diversidade de alunos. Contribuir para superar tanto a atitude de indiferença quanto a de intolerância ante a diversidade, na defesa de uma proposta de educação para a igualdade de dignidade e de oportunidades.

\section{O Núcleo de Educação Inclusiva}

O debate sobre a inclusão passou a ser acolhido pela UFOP em meados da década de 1990, momento quando começou a receber demandas de candidatos com algum tipo de deficiência nos processos seletivos para a entrada nos cursos de graduação. Desde então, a UFOP busca garantir a implantação de uma Política de Educação Inclusiva, desenvolvendo ações por meio do Núcleo de Educação Inclusiva (NEI) da Pró-Reitoria de Graduação. 
O NEI/UFOP foi criado em 2006 pelo Conselho Universitário (Cuni) e pelo Conselho de Ensino, Pesquisa e Extensão (Cepe), conforme determinação do Programa de Acessibilidade ao Ensino Superior - Incluir. De acordo com o Regimento Interno, aprovado na Resolução Cuni 790/2006, o objetivo do NEI é eliminar barreiras atitudinais, físicas, comunicacionais, entre outras, que restrinjam a participação e o desenvolvimento acadêmico e social de estudantes com deficiência de forma articulada com os diversos setores da instituição, como departamentos, colegiados de cursos, entre outros, visando à igualdade de direitos e o respeito às diferenças.

Quando se realiza a matrícula de um estudante com deficiência, a UFOP, por meio do NEI, inicia o processo de escuta. Esse é o momento em que o aluno expõe suas necessidades educacionais específicas, expressando deficiência e demandas. Por conseguinte, o NEI pode conhecer as especificidades do aluno, apresentando-lhe estruturas de apoio e recursos humanos, pedagógicos e instrumentais. Antes que ele inicie as atividades na sala de aula, o NEI contata o colegiado de curso e os professores, para conhecimento das demandas do aluno, e elaboram, conjuntamente, o Plano de Desenvolvimento Inclusivo (PDIn), que indica ações de inclusão. Durante todo o percurso acadêmico do aluno, o Núcleo, o colegiado de curso e os professores acompanhamno/orientam-no, de acordo com o estabelecido no PDIn.

A escuta feita por esse Núcleo é uma forma de possibilitar o conhecimento do "outro", do diferente. O NEI disponibiliza aos estudantes um conjunto de Tecnologias Assistivas, como leitores de tela, impressores em braille, materiais didáticos em formatos acessíveis, intérpretes de Libras, entre outros, fundamentais para a autonomia dos estudantes. Entretanto, não são esses os motivos que o tornam inovador. A inovação está exatamente na possibilidade de desenvolver ações pedagógicas concretas, articuladas com os distintos setores da Instituição, capazes de respeitar as diferenças dos alunos e de integrá-las em uma unidade que não as anule (FLEURI, 2003).

Silva (2016), ao investigar o processo de inclusão de estudantes com deficiência na UFOP, revelou que o trabalho desenvolvido por esse Núcleo contribuiu para provocar em alguns docentes o desejo de inovar-se pedagogicamente, visando à inclusão de seus alunos. A autora ressaltou as contribuições da inovação pedagógica na construção do processo de ensino e de aprendizagem de alguns estudantes com deficiência na Instituição. Uma questão e desafio apresentados em seu estudo referiam-se ao PDIn de uma estudante deficiente visual. A estudante matriculou-se na disciplina Introdução a Libras, que implica 
exploração visual. Diante da situação, desejava saber como a professora faria para ensinarlhe o conteúdo e como sua participação se efetivaria. A professora, que até o momento não havia trabalhado com estudante com baixa visão, reuniu-se com o Núcleo de Educação Inclusiva para discutir a demanda e uma das propostas foi a contratação de um monitor para ajudá-la no processo de ensino e aprendizagem. Para a docente representou, inicialmente, um grande desafio, porém foi perceptível a sua compreensão de que o processo de ensino e de formação passa, necessariamente, por aprender a lidar com o novo, com aquilo que nos desloca. É preciso correr riscos, rejeitar qualquer forma de discriminação e refletir criticamente sobre a prática.

Silva (2016, p. 139-140) apresentou, a partir do relato da própria estudante, o caminho metodológico utilizado pela professora para ensinar Libras a toda a turma, considerando, principalmente, as diferenças ali existentes.

Eu tive uma experiência muito, muito, muito boa com a disciplina de Libras. Tive uma monitora, que me passava tudo o que a professora ensinava de sinais. Ela fazia tudo na minha mão para que eu pudesse ter acesso. Ela fazia os sinais e eu com a mão junto da mão dela. Para que eu pudesse ter acesso àquilo e pudesse aprender. E aprendi (Entrevista concedida por Marta, em 16/07/2015).

A professora não tinha experiência em dar aulas de Libras para estudantes com baixa visão, então, a gente foi descobrindo como fazer, eu, a professora e a monitora. De que forma a gente poderia fazer tudo da disciplina em igualdade com os outros colegas, no mesmo tempo, mas respeitando as minhas diferenças e apoiando em outros recursos (Entrevista concedida por Marta, em 16/07/2015).

O trabalho articulado levou à criação de novas práticas educativas inclusivas e diferentes formas de relacionamento e atuação entre docente e aluno (AINSCOW, 2009; SANTOS 2003). Diante do novo, do estranho aos olhos conformados com uma visão universal de estudante, a professora não repeliu suas ideias, seus pensamentos e inovou-se pedagogicamente. A mudança envolveu uma ação concreta, localizada num contexto de aprendizagem relativamente incomum, e provocou transformações nos envolvidos: a professora, a estudante com baixa visão, o Núcleo de Educação Inclusiva e os demais estudantes videntes que também cursaram a disciplina. Estes últimos tiveram a oportunidade de vivenciar o fazer inclusivo na prática e de constatar que esse fazer beneficia a todos os envolvidos e que tem a ver diretamente com cada um de nós.

A inovação pedagógica pressupõe a abertura para a manifestação do diferente carregada de intencionalidade (FRANCO, 2015). Os núcleos de acessibilidade e inclusão 
podem ser articuladores na criação e valorização de propostas inclusivas e inovadoras no interior das universidades, organizando-se para concretizar determinadas expectativas educacionais. As ações inclusivas precisam ser ampliadas para além de esforços individuais dos docentes, passando pela construção e efetivação de políticas institucionais educacionais que visem à formação e às práticas mais efetivas. A presença de estudantes com deficiência exige das universidades novos posicionamentos e procedimentos de ensino, fundamentados em concepções e práticas pedagógicas inovadoras que valorizem e respeitem a diversidade humana.

\section{O Programa Sala Aberta}

O Núcleo de Apoio Pedagógico da UFOP, criado em meados da década de 1990, promove ações que visam garantir a implantação de um programa de formação docente. Ele considera que os professores são atores fundamentais no desenvolvimento de culturas, políticas e práticas capazes de promover a inclusão de seus estudantes.

Nesse sentido, em 2013, foi reestruturado o Programa Sala Aberta: Docência no Ensino Superior, que ampliou, por meio de encontros presenciais e virtuais, teóricos e práticos, espaços para o diálogo e a permanente reflexão sobre os desafios da docência universitária, tendo como protagonistas os próprios professores. Os encontros acontecem uma vez por mês e envolvem docentes dos diferentes cursos da UFOP. O objetivo principal é oferecer aos professores espaços de discussão e de busca de alternativas para o enfrentamento dos desafios da docência. Um dos eixos de formação é a emergência de práticas pedagógicas inovadoras no contexto da UFOP.

Para Fino (2008), a inovação pedagógica implica mudanças de atitude do professor, que ocorrem de dentro para fora, resultando em reflexão, criatividade, crítica e autocrítica, aceitação das diferenças, rejeição a qualquer forma de discriminação. Embora a disposição para inovar-se pedagogicamente dependa de uma organização interna de cada docente, o Programa Sala Aberta constituiu-se como uma valiosa ferramenta na proposição da construção de práticas pedagógicas que respeitem o outro na sua alteridade.

Ao enfatizar o caráter relacional e contextual dos processos da docência na UFOP e a necessidade de propostas pedagógicas que possam contribuir para redução das taxas de retenção, evasão e elevação dos índices de aproveitamento acadêmico, o Sala Aberta permitiu reconhecer a complexidade do processo de ensino e aprendizagem, incorporando

RIAEE - Revista Ibero-Americana de Estudos em Educação, Araraquara, v. 13. n. esp. 2, p. 1320-1333, set., 2018. ISSN: 1982-5587. 
a noção de democracia, respeito e valorização das diferenças humanas. Nesse sentido, conforme Cunha (2006), a inovação pedagógica é tomada numa perspectiva de ruptura paradigmática.

O Sala Aberta da UFOP, espaço de discussão entre docentes de diferentes áreas do conhecimento, pode ser entendido como essencial para compreender a inclusão educacional como um processo de transformação de valores em ação (AINSCOW, 2009).

\section{As ações extensionistas como propositoras de práticas pedagógicas inovadoras e inclusivas}

A Universidade Federal de Ouro Preto desenvolve, por meio de sua Pró-Reitoria de Extensão, diversos projetos e programas que buscam aproximar a Instituição da comunidade regional. No campo da inclusão e da inovação pedagógica, a ação da universidade ainda se faz tímida. A atuação acaba por se concentrar, com mais ênfase, no campo das Humanas do que em outras áreas de conhecimento.

Optamos por apresentar aqui um dos projetos de extensão que tem em sua proposta uma perspectiva de formação inicial e continuada. Por estarmos abordando ações no Ensino Superior, escolhemos fazer um recorte do projeto evidenciando então a sua perspectiva de formação inicial. O projeto de extensão tem utilizado os princípios da pesquisa-ação como forma de orientar as suas ações (BARBIER, 2007; THIOLLENT, 2011), cujo objetivo é compreender as práticas pedagógicas de professores que atuam com crianças público-alvo da educação especial, bem como, de forma conjunta, refletir sobre essas práticas e repensá-las. Para tanto e para a sua reelaboração, o projeto propõe que alunos de graduação atuem nas escolas parceiras e sejam supervisionados/orientados pela coordenação do projeto. Os estudantes de graduação acompanham o trabalho do professor em sala de aula e, sob orientação da coordenação do projeto, buscam dialogar com os professores da educação básica sobre possibilidades de se (re)pensar o trabalho pedagógico de forma mais inclusiva, considerando as realidades que vivenciam.

Entendemos que a formação de professores, por via de regra, não tem respondido às necessidades e demandas que se apresentam no cenário nacional. É preciso enfrentar uma variedade de problemas na formação do professor, que se acumulam historicamente (GATTI, 2014). No campo da inclusão, esse fator se apresenta de forma mais enfática. Conforme Glat e Pletsch (2011, p. 119): 
[...] a falta de habilidade específica de professores do ensino regular para lidar com alunos que apresentam necessidades educacionais especiais é uma das principais barreiras a serem vencidas na implantação efetiva de uma educação inclusiva.

Para as autoras, não se pode esperar que professores que não possuem conhecimentos e experiências formativas na área possam desenvolver práticas de ensino que levem em consideração a grande diversidade de aprendizagem que ocorre nas salas de aula, o que nos remete ao fato de repensarmos os modelos de formação docente que se apresentam. Nesse caso, a pesquisa-ação tem se configurado como uma possibilidade de qualificar o debate acerca da formação do professor. Contribuindo com esse debate e refletindo sobre a necessidade de modelos inovadores, Lucarelli (2008) questiona o papel que a universidade vem cumprindo ao longo de décadas como instituição formadora. Para a autora, a universidade tem valorizado, ao longo do tempo, a imagem do docente conhecedor dos conteúdos a serem transmitidos no processo de ensino e de aprendizagem, como se o domínio do conteúdo garantisse a qualidade desse processo.

Considerando tal perspectiva, o modelo extensionista adotado tem respondido, positivamente, à qualificação da formação daqueles que vivenciam as experiências proporcionadas no projeto. Ao longo de quatro anos, o projeto recebeu um número de 23 alunos de graduação (bolsistas), que atuaram diretamente nas escolas com os professores em salas de aulas. Esses bolsistas acompanharam as crianças com deficiência em salas de aula buscando compreender suas especificidades. O conhecimento adquirido nesse acompanhamento alimenta o diálogo com o professor no intuito de se construírem práticas mais inclusivas.

Questionamo-nos então, sobre o lugar da inovação pedagógica nessa ação extensionista. Ela se dá exatamente na possibilidade de o aluno de graduação vivenciar o cotidiano da sala de aula tentando compreender a relação ensino-aprendizagem em um ambiente que demanda uma atenção maior às diferenças. Nos encontros quinzenais para estudos teórico-metodológicos sobre o tema e nos encontros semanais para discussão dos casos e orientação, privilegia-se a reflexão como forma de construção de um modelo emancipatório da ação pedagógica (Veiga, 2003). Busca-se, aqui, compreender a necessidade de se apropriar do conhecimento científico como forma de subsidiar e orientar as ações da prática reflexiva. Os alunos de graduação assumem o protagonismo nas salas de aula, uma vez que passam a se preparar e a se formar para uma atuação específica que considera o conhecimento científico como base de elaboração e reflexão sobre sua ação.

RIAEE - Revista Ibero-Americana de Estudos em Educação, Araraquara, v. 13. n. esp. 2, p. 1320-1333, set., 2018. ISSN: $1982-5587$. 
Além disso, ele se vê diante do desafio de dialogar com um professor, profissional formado, que atua há anos na sala de aula e que, na maioria das vezes, lhe diz que não sabe o que fazer ou como agir para o processo inclusivo de seu aluno.

O projeto trabalha a concepção de uma dupla formação. Uma mais diretamente ligada ao aluno da graduação e outra indiretamente focada no professor da educação básica. O resultado que temos visto a partir de pesquisa com os sujeitos desse projeto é que os alunos de graduação têm sido unânimes em dizer que as experiências que vivenciaram foram fundamentais para que pudessem começar a compreender o processo de inclusão no campo da educação especial. Falas que evidenciam o desejo de atuar mais no campo da educação especial e da inclusão a partir da participação no projeto e outras que revelam a apropriação de determinados conhecimentos científicos se repetem nos depoimentos dos alunos. É importante ressaltar que a experiência do projeto ainda está longe de ser algo no campo do ideal, porém revela possibilidades de pensar a formação do professor em diálogo mais próximo com a educação básica, por meio da adoção dos princípios do modelo de pesquisa-ação. Para Franco (2015), a pedagogia da mudança pauta-se em postura problematizadora que objetiva a formação de sujeitos visando uma prática reflexiva e emancipadora. O professor que dialoga sobre suas experiências e concepções revela um espírito investigativo que pode contribuir para a produção de conhecimento e para a sua formação (CUNHA, 2008).

\section{Considerações finais}

A construção de uma universidade inovadora e inclusiva depende de uma política institucional efetiva. Ações isoladas não são suficientes para promover a inclusão e podem se revelar empecilho para novos avanços, uma vez que podem ser identificadas como suficientes. Sem avaliação articulada no âmbito das políticas, das culturas e das práticas inclusivas (SANTOS, 2003), as reais demandas dos estudantes podem ser camufladas, além de contribuir para a cristalização de uma imagem universal e homogeneizante de estudante universitário.

Considera-se, nesse sentido, que criar oportunidades para que os alunos tenham acesso ao Ensino Superior é fundamental para o processo de democratização desse nível de ensino, porém não é suficiente. É necessária a existência de um conjunto de ações que assegurem, de fato, a igualdade de participação, o respeito e valorização das diferenças 
humanas. Nós, educadores, somos atores-chave no desenvolvimento de práticas pedagógicas inovadoras no intuito de promover uma educação mais inclusiva. A cultura institucional inclusiva parte do princípio de que todos são responsáveis pela vida da instituição e qualquer desafio nela ocorrido é da responsabilidade de todos, e não de apenas uma pessoa ou um segmento da comunidade acadêmica. A universidade que caminha sob essa perspectiva compreende que é necessário trabalhar em rede e ouvir seus estudantes, seus docentes e toda a comunidade acadêmica, resgatando os sujeitos deste processo e as considerações subjetivas implicadas.

\section{REFERÊNCIAS}

AINSCOW, M. Tornar a educação inclusiva: como essa tarefa deve ser conceituada? In: FÁVERO, O. et al. (Org.). Tornar a educação inclusiva. Brasília: Unesco, 2009. p. 1123.

BARBIER, R. A pesquisa-ação. Tradução de Lucie Didio. Brasilía: Liber Livro, 2007.

BUENO, J. G. S. As pesquisas e a produção do conhecimento em educação especial: as investigações sobre políticas de educação especial no Brasil. Distúrb Comun, São Paulo, v. 24, n. 3, p. 285-297, dez. 2012.

CUNHA, M. I. (Org.). Pedagogia universitária: energias emancipatórias em tempos neoliberais. Araraquara: Junqueira \& Marin, 2006.

CUNHA, M. I. Inovações pedagógicas: o desafio da reconfiguração de saberes na docência universitária. São Paulo: Edusp, 2008. (Coleção Cadernos de pedagogia universitária, caderno 6.)

CUNHA, M. I. Inovações na educação superior: impactos na prática pedagógica e nos saberes da docência. Em Aberto, Brasília, v. 29, n. 97, p. 87-101, set.-dez. 2016.

FINO, C. N. Inovação pedagógica: significado e campo (de investigação). In: MENDONÇA. Alice; BENTO, António V. (Org.). Educação em tempo de mudança. Funchal: Grafimadeira, 2008. p. 277-287.

FLEURI, R. M. Intercultura e educação. Revista Brasileira de Educação, n. 23, p. 16-35, 2003.

FRANCO, M. A. S. Práticas pedagógicas de ensinar e aprender: entre resistências e resignações. Educ. Pesqui., São Paulo, v. 41, n. 3, p. 601-614, jul.-set. 2015.

GATTI, B. A. Critérios de qualidade. PGM 1 - Formação de Professores a Distância. 2014. Disponível em: <http://www.ufrgs.br/nucleoead/documentos/educacao2.htm>. Acesso em: 01 maio 2015. 
GLAT, R.; PLETSCH, M. D. Inclusão escolar de alunos com necessidades educacionais especiais: políticas, práticas pedagógicas e cultura escolar. Rio de Janeiro: Editora Eduerj, 2011.

LUCARELLI, E. Asesoría pedagógica y cambio en la Universidad. Profesorado. Revista de Currículum y Formación del Profesorado, v. 12, n. 1, 2008. Disponível em:

<http://www.ugr.es/local/recfpro/rev121ART7.pdf>.

LÜDKE, M.; ANDRÉ, M. E. D. A. Pesquisa em educação: abordagens qualitativas. São Paulo: EPU, 1986.

SANTOS, M. P. dos. O papel do Ensino Superior na proposta de uma educação inclusiva. Revista Movimento, Faculdade de Educação da UFF, n. 7, p. 78-91, maio 2003.

SILVA, M. M. da. Processo de inclusão no Ensino Superior: o caso de estudantes com deficiência na Universidade Federal de Ouro Preto. 2016. 251f. Dissertação (Mestrado em Educação) - Programa de Pós-graduação em Educação, Universidade Federal de Ouro Preto, Ouro Preto.

THIOLLENT, M. Metodologia da pesquisa-ação. 18. ed. São Paulo: Cortez, 2011.

TOFFLER, Alvin. Choque do futuro. Lisboa: Edição Livros do Brasil, 1970.

VEIGA, I. P. A. Inovações e projeto-pedagógico: uma relação regulatória ou emancipatória? Caderno Cedes, Campinas, v. 23, n. 61, dez. 2003.

\section{Como referenciar este artigo}

FRANCO, Marco A. Melo.; SILVA, Marcilene Magalhães da.; TORISU, Edmilson Minoru. Inclusão e inovação pedagógica: políticas e práticas de formação no Ensino Superior. Revista Ibero-Americana de Estudos em Educação, Araraquara, v. 13. n. esp. 2, p. 1320-1333, set., 2018. ISSN: 1982-5587. DOI: 10.21723/riaee.v13.nesp2.set2018.11646

Recebido em: 15/02/2018

Aprovação final: 04/07/2018 